\title{
Statistical Wind Energy Analysis and Wind Persistence Assessment for Cordoba And Sucre Departments' Weather Stations in The Caribbean Region of Colombia
}

\author{
Jonathan Fabregas Villegas ${ }^{\mathrm{a}, \mathrm{b}}$, Guillermo Valencia Ochoa ${ }^{\mathrm{c}, 1}$, Marley Vanegas Chamorro ${ }^{\mathrm{c}, 2}$ \\ ${ }^{a}$ Universidad Autónoma del Caribe, Colombia \\ E-mail: jonathan.fabregas@uac.edu.co \\ ${ }^{b}$ Project Management, Universidad Benito Juarez G., México \\ ${ }^{c}$ Universidad del Atlántico, Colombia, Kaí \\ E-mail: ${ }^{\text {g }}$ uillermoevalencia@mail.uniatlantico.edu.co, ${ }^{2}$ marleyvanegas@mail.uniatlantico.edu.co
}

\begin{abstract}
A statistical analysis is carried out on the behavior of wind speed at meteorological stations located in the Caribbean Region of Colombia, in order to establish and identify the potential available in wind energy to be used as a renewable energy source, this by through the use of rigorous periodic studies, carried out by the Colombian Institute of Environment, Meteorology and Hydrology (IDEAM), to have efficient energy management and encourage the start-up of wind farms, which satisfy the energy demand necessary for the supply of Vulnerable Populations in the Colombian nation, therefore, the meteorological stations and their location are described, a wind analysis is made at different heights and roughness of the study terrain, and wind persistence studies are carried out using the autocorrelation function (ACF), behavioral analyzes are made Hourly and annual wind rate, for the meteorological stations described, in addition, graphs of the wind direction or wind roses are presented, with greater stability in the annual periods. From which an analysis could be established that allows the use of wind energy potential to be viewed by adequately reaching the behavior of the wind for meteorological stations in the departments of Córdoba and Sucre located in the Caribbean Region. The department of Córdoba presents, according to its meteorological stations, an average wind speed value ranging from 1.3 $\mathrm{m} / \mathrm{s}$ to $1.4 \mathrm{~m} / \mathrm{s}$, while in the department of Sucre, values of average wind speed of $0.85 \mathrm{~m} / \mathrm{s} \mathrm{to} 1.7 \mathrm{~m} / \mathrm{s}$.
\end{abstract}

Keywords — wind roses; wind persistence; wind speed; auto-correlation function.

\section{INTRODUCTION}

Recently in the Colombian territory, new solutions are proposed to supply electricity to the interconnected national sector through the investigation of clean energies, such as solar and wind energy. However, the nation is currently mostly provided by hydroelectric and thermoelectric plants. Generating irreversible damages is at an environmental level. Preparing for energy rationing through the application of clean energy is the task indicated for the energy development of Colombia. Pasqualino et al. [1].

It is shown in statistics since 2012. In Colombia, electricity generation has been supplied by the following sources, $64 \%$ in hydroelectric plants, 30.8\% in thermoelectric plants, and $4.8 \%$ in small-scale power plants. In 2015, there was a demand for 65,000 GWh, and for 2019 it was estimated at $75,000 \mathrm{GWh}$, which shows a trend of increasing energy use. Therefore, if the climatic records by the IDEAM are taken, it shows the wind and radiation data. Wind behavior studies are achieved and thus obtain the amount of wind energy generation that would contribute to and supply the national demand for energy. This to encourage the construction and financing of projects focused on this type of energy.

There are numerical model tools for verification of wind movements such as the Navier-Stokes equations, and visualization tools such as Wind Atlas. Troen et al. [2]. A method estimates through curves of wind speed duration and Weibull theoretical curves adjustment method [3]. In works carried out by Cancino et al. [4] the wind properties of the State of Veracruz Mexico are studied, analyzing the wind persistence for the possible construction of wind farms, achieving favorable results, indicating that the areas evaluated are suitable for wind power generation. On other studies of Cancino et al. [5] developed a study on the energy demand for the energy supply in the country of Mexico, in 
which they compared the different sources of energy generation and the wind panorama for five meteorological stations located in the state of Veracruz, therefore, Ahmet and Güler [6] propose a very precise estimation method for the Weibull equations used for the characterization of the wind which in turn is compared with the alternative methods of maximum likelihood, power density method, among others, achieving that its proposed new method is suitable for calculating the Weibull Distributions, while Jiang L [7] studied the characteristics of the wind to implement the method of analysis of fluctuation in China, consequently, the persistence of the wind in the long term is established obtaining data that indicate percentages that tend to the low to the west of China, so Z.R. Shu et al. [8] they made a characterization of the environmental effects in weather stations located in the southwest of China, where the impact of wind speed along with the veering angle are analyzed to identify the importance of the properties that affect the dependence of the variation of the wind direction at different heights of the study, therefore, it is considered to perform an analysis of the wind characteristics in weather stations located in the departments of Córdoba and Sucre in the Caribbean region of Colombia, reviewing the records provided by the IDEAM for the periods from the last two decades.

\section{MATERIALS AND METHOD}

\section{A. Weather Stations Description and Location}

The Department of Córdoba is in the Caribbean Region towards the northwestern area of the Colombian geography, and it is placed within $7^{\circ} 22^{\prime} \mathrm{N}-9^{\circ} 26^{\prime} \mathrm{N}$ latitude and $74^{\circ} 47^{\prime} \mathrm{W}$ - $76^{\circ} 30^{\prime} \mathrm{W}$ longitude coordinates, encompassing a surface of $23,980 \mathrm{~km}^{2}$ which pertains to $18 \%$ corresponding to the surface of the Colombian Caribbean Region. Department of Sucre is located on the Caribbean Region on the northern area of the country, placed at $9^{\circ} 18^{\prime} \mathrm{N}$ latitude and $75^{\circ} 24^{\prime} \mathrm{W}$ longitude with a surface area of $10,679 \mathrm{~km}^{2}$ that encompass $8.08 \%$ of the total Colombian Caribbean surface area [9][11]. The location of the studied weather stations is shown in table 1 and figure 1, which are Turipaná, Los Garzones Airport, UniCórdoba, UniSucre, and Primates.

TABLE I

COORDINATES OF THE SELECTED WEATHER STATIONS

\begin{tabular}{|l|l|l|}
\hline Station & Latitude & Longitude \\
\hline Turipaná & $08^{\circ} 53^{\prime} 13^{\prime \prime} \mathrm{N}$ & $75^{\circ} 47^{\prime} 29^{\prime \prime} \mathrm{W}$ \\
\hline UniCórdoba & $08^{\circ} 47^{\prime} 17^{\prime \prime} \mathrm{N}$ & $75^{\circ} 51^{\prime} 29^{\prime \prime} \mathrm{W}$ \\
\hline Los Garzones Airport & $08^{\circ} 49^{\prime} 26^{\prime \prime} \mathrm{N}$ & $75^{\circ} 49^{\prime} 34^{\prime \prime} \mathrm{W}$ \\
\hline UniSucre & $09^{\circ} 18^{\prime} 01^{\prime \prime} \mathrm{N}$ & $75^{\circ} 23^{\prime} 01^{\prime \prime} \mathrm{W}$ \\
\hline Primates & $09^{\circ} 31^{\prime} 01^{\prime \prime} \mathrm{N}$ & $75^{\circ} 21^{\prime} 01^{\prime \prime} \mathrm{W}$ \\
\hline
\end{tabular}

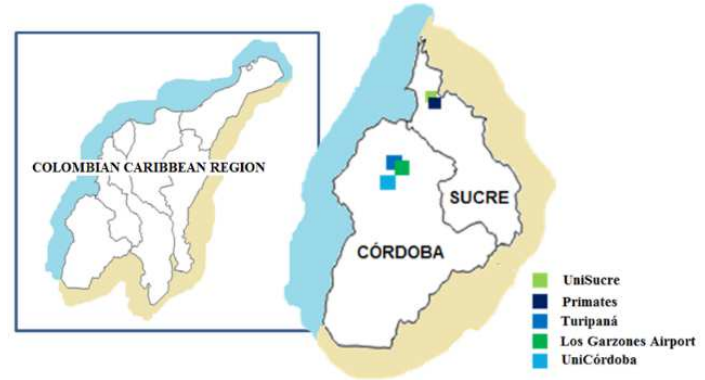

Fig. 1 weather stations in Córdoba and Sucre

\section{B. Wind Analysis at Different Heights and Roughness}

The roughness presents obstacles that affect the direction and speed of the wind to an even though the study is carried out at different heights on the terrestrial surface, which leads to implementing a method that, based on a soil survey, establishes the roughness factor as a dependent variable for wind speed. Therefore, an exponential model called the Hellmann law is used. It estimates the wind behavior starting from a measured speed at $10 \mathrm{~m}$ of initial height and the roughness factor to estimate the wind speed at different heights. The towers Winds are used up to more than $100 \mathrm{~m}$ height; consequently; then equation (1) establishes Hellmann law. [12], [13].

$$
\frac{v}{v_{0}}=\left(\frac{h}{h_{0}}\right)^{\alpha}
$$

Where the variables shown in the previous equation represent the following terms, $v_{0}$ is the registered wind speed at a reference height $h_{0}$ with a value of $10 \mathrm{~m}, h$ is the next height at which it is required to calculate the wind speed $v$, the value $\alpha$ corresponds to the environment roughness.

\section{Wind Persistence Methods}

An analysis of wind, persistence performs the wind speed records obtained by IDEAM are used, implementing the autocorrelation function (ACF) to identify repetitive patterns, which allows estimating the value of wind persistence, these values are calculated using equations 2 to 4 below.

$$
\begin{gathered}
r_{k}=\frac{\sum_{i=1}^{n-k}\left(v_{i}-\bar{v}\right)\left(v_{i+k}-\bar{v}\right)}{\sum_{i=1}^{n}\left(v_{i}-\bar{v}\right)^{2}} \\
P_{A C F}=\frac{1}{2} r_{1}\left(k_{0}-1\right) \\
P_{A C F}=\frac{1}{2} r_{1}\left(k_{m}-1\right)
\end{gathered}
$$
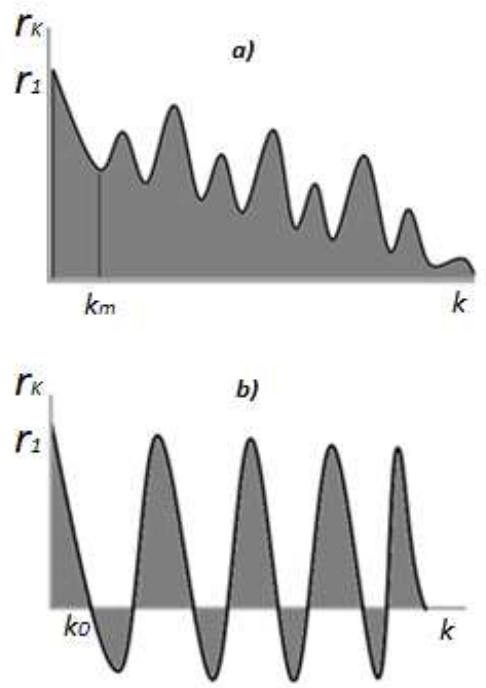

Fig. 2 ACF: a) location of $k_{m}$, b) location of $k_{0}$ 
Where the variable $r k$ indicates the coefficient of autocorrelation of the function, $k$ defines the delay value of the function, $n$ indicates the number of inputs in the function, $v$ represents the average wind speed, consequently relating the equations (2-4) the value corresponding to the autocorrelation function (PACF) can be obtained. Moreover, it establishes the value of the persistence of the wind for each of the meteorological stations to be studied. Cancino et al. [4]. Figure 2 points out the attainment of the delay values. The previous figure indicates the areas of the function that are used to estimate the persistence of the wind, so $k_{m}$ indicates the minimum value of the first oscillation of the function and $k_{0}$ shows the intersection with the axis $\mathrm{k}$ for the first oscillation of the function.

\section{RESULTS AND DISCUSSION}

\section{A. Wind Speed Analysis for the Weather Stations}

The behavior of the wind for the weather stations located in Turipaná, Los Garzones Airport, UniCórdoba, UniSucre, and Primates was analyzed. The behavior of the wind speed is shown in graphs, evaluated by months, years, and height of measurement, as shown in Figures 3, 4, and 5 below.

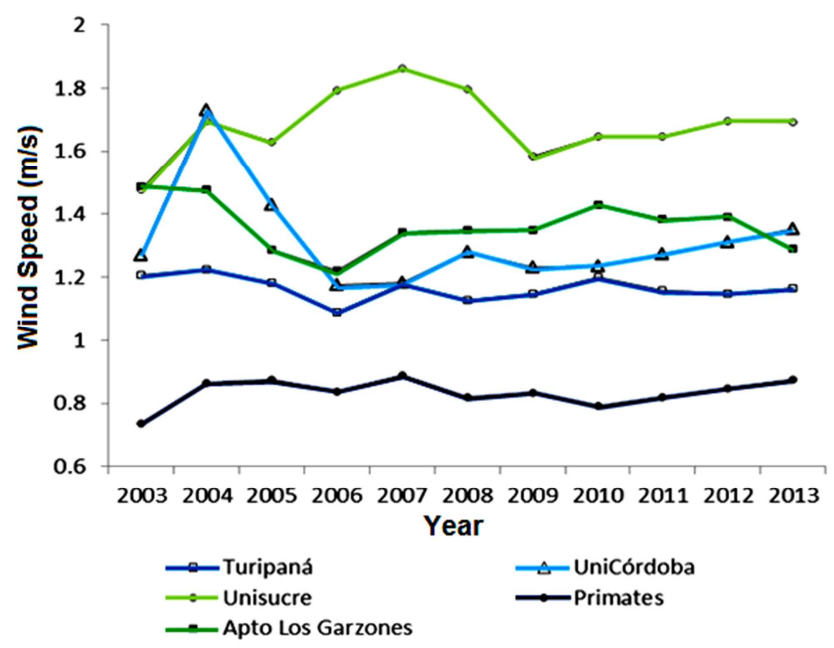

Fig. 3 Annual average wind speed

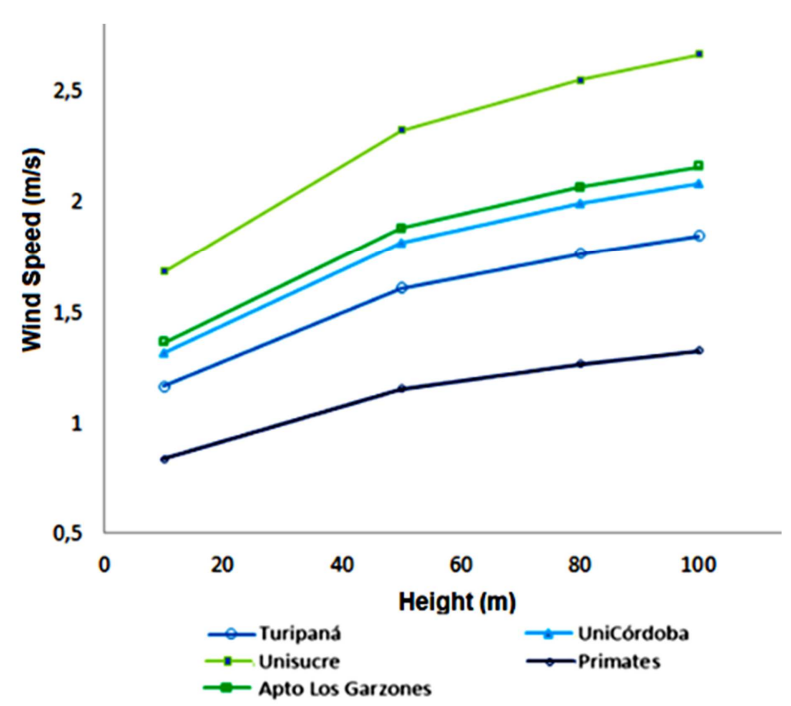

Fig. 4 Estimation of wind speed according to the height
Figure 4 shows the variation wind speed with height, this using Equation 1 of the Hellmann model, thus obtaining the value of the wind speed from $10 \mathrm{~m}$ to $100 \mathrm{~m}$ in height. The values reached are a $50 \%$ increase in wind speed from a base height.
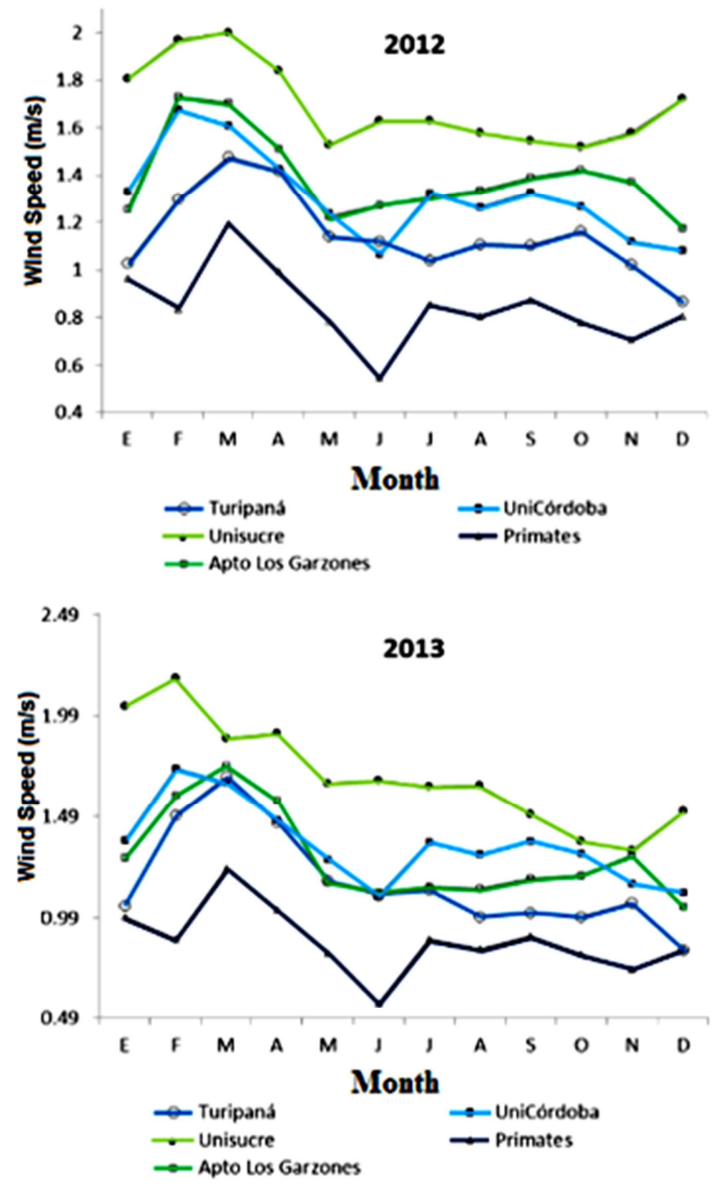

Fig. 5 Mean wind speed in monthly periods

The value of the monthly wind speed was averaged from the periods from 2003 to 2013, obtaining figure 5, which shows the variation in wind speed from January to December. Besides, it is observed that for the first months of the year, the value of the wind speed is higher than the rest of the year for the weather stations located in the departments of Sucre and Cordoba.

Therefore, in the previous figures it can be analyzed that the wind speed tends to be maximum for February and march, UniSucre with an average wind speed of $2 \mathrm{~m} / \mathrm{s}$, UniCordoba with an average wind speed of $1.5 \mathrm{~m} / \mathrm{s}$ as well as the station of Apto Los Garzones, the Turipana station with an average wind speed of $1.45 \mathrm{~m} / \mathrm{s}$, and the Primates station with an average wind speed of $1.0 \mathrm{~m} / \mathrm{s}$. Consequently, the speed values recorded in the previous figures for annual periods have tended to be constant for weather stations, except for the UniSucre and UniCordoba stations, which show variations in their annual period.

\section{B. Hourly Wind Behavior for the Weather Stations}

Hence, the behavior of wind across time for the five surveyed stations shows the mean wind speed attained every 24 hours, as it is shown in figure 6 . Reaching a mean speed behavior of $0.85 \mathrm{~m} / \mathrm{s}$ for the Primates station, $1.7 \mathrm{~m} / \mathrm{s}$ for the 
UniSucre station, $1.4 \mathrm{~m} / \mathrm{s}$ for the Los Garzones Airport station, $1.35 \mathrm{~m} / \mathrm{s}$ for the UniCórdoba Station and $1.15 \mathrm{~m} / \mathrm{s}$ for the Turipana station. The previous values show usable wind energy potential. Having the highest wind speed peaks between 7 am and $10 \mathrm{pm}$.
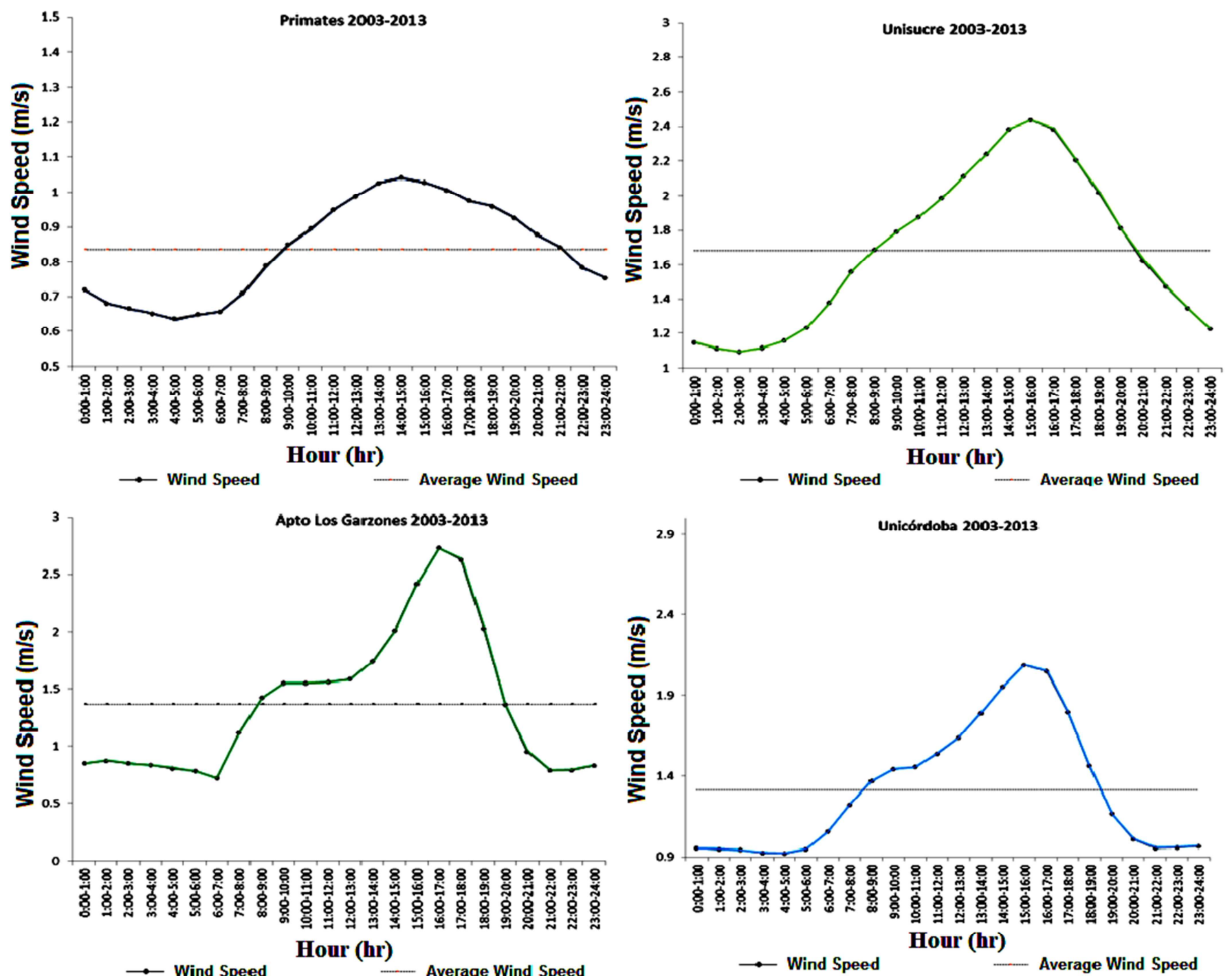

$\rightarrow$ Wind Speed
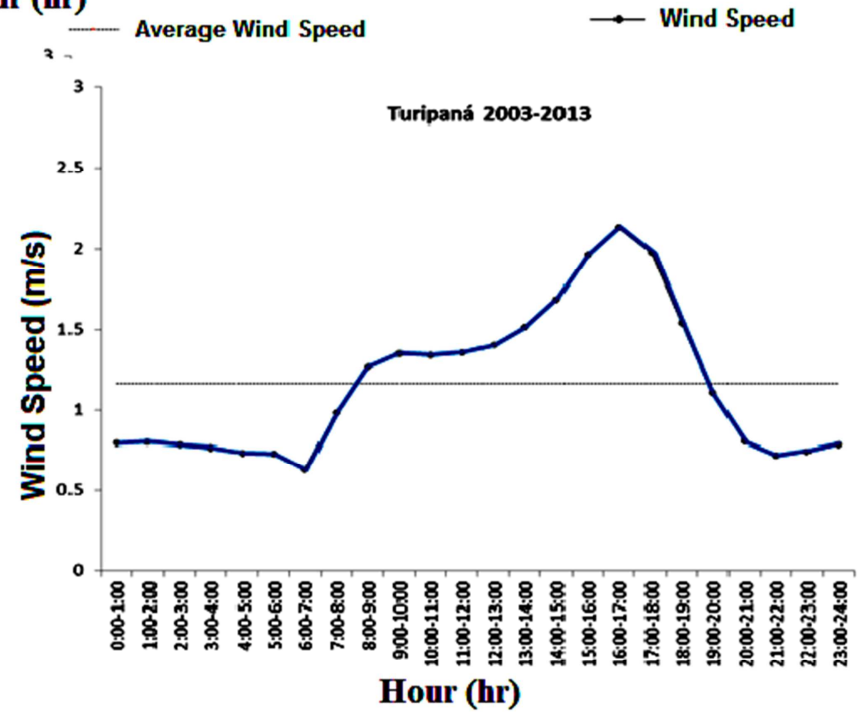

$\longrightarrow$ Wind Speed

Average Wind Speed

Fig. 6 Hourly measurement of wind speed 


\section{Wind Persistence Analysis for The Weather Stations}

Through working out equations 2,3 and 4 , the corresponding values to the auto-correlation function (ACF) are obtained for each station, which is stated in Table II whose functions are shown in figure 7 . The values of the auto-correlation functions obtained for each weather station are 2.70 for Turipaná, 2.10 for the Los Garzones Airport, 105.23 for UniCórdoba, 3.28 for UniSucre. They were showing that persistence indicators were attained for all the surveyed stations. Consequently, the UniCórdoba station indicator the highest of all [11].

The graphs indicate in two boxes in figure 7 , the first maximum value (peak value) of the ACF on the y-axis, and the intersection with the $\mathrm{x}$-axis or the first minimum value of a curve of the function, the latter for functions that do not cut the $\mathrm{x}$-axis. The weather stations of Los Garzones Airport,
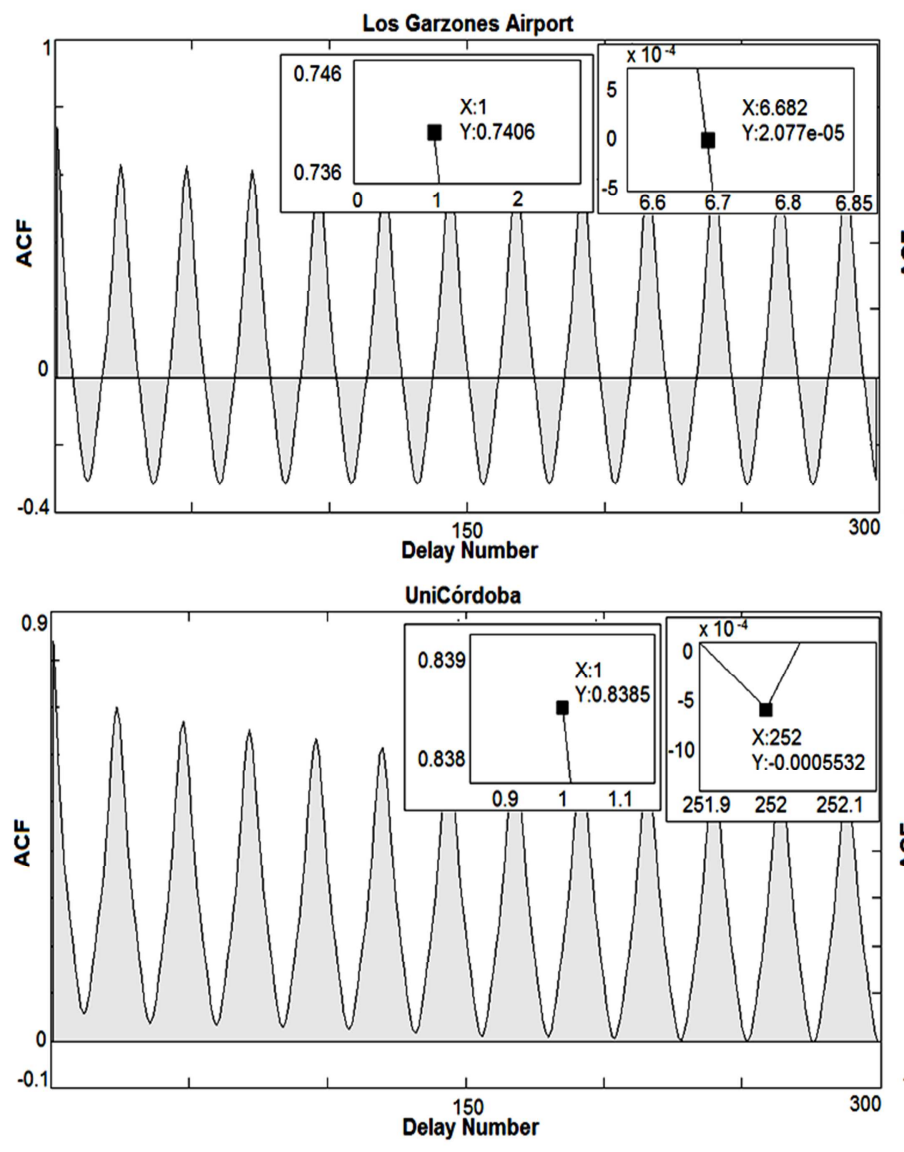

Fig. 7 Auto-correlation Function

\section{Wind Roses for The Weather Stations}

The wind direction is an important factor in measuring the wind potential observed at one station [14], [15]. Figure 8 shows the direction behavior of the wind on the five surveyed stations. Showing the direction for each station where the wind speed persistence can be used, moreover, in figure 8 of Wind Roses, it can be seen that the weather stations of Turipana, UniCòrdoba, and Apto. Los Garzones encompass a greater range of wind gain in the southwest direction, while UniSucre and Primates stations show a range of use of wind in direction South East and North East respectively. It should be noted that the station with the best
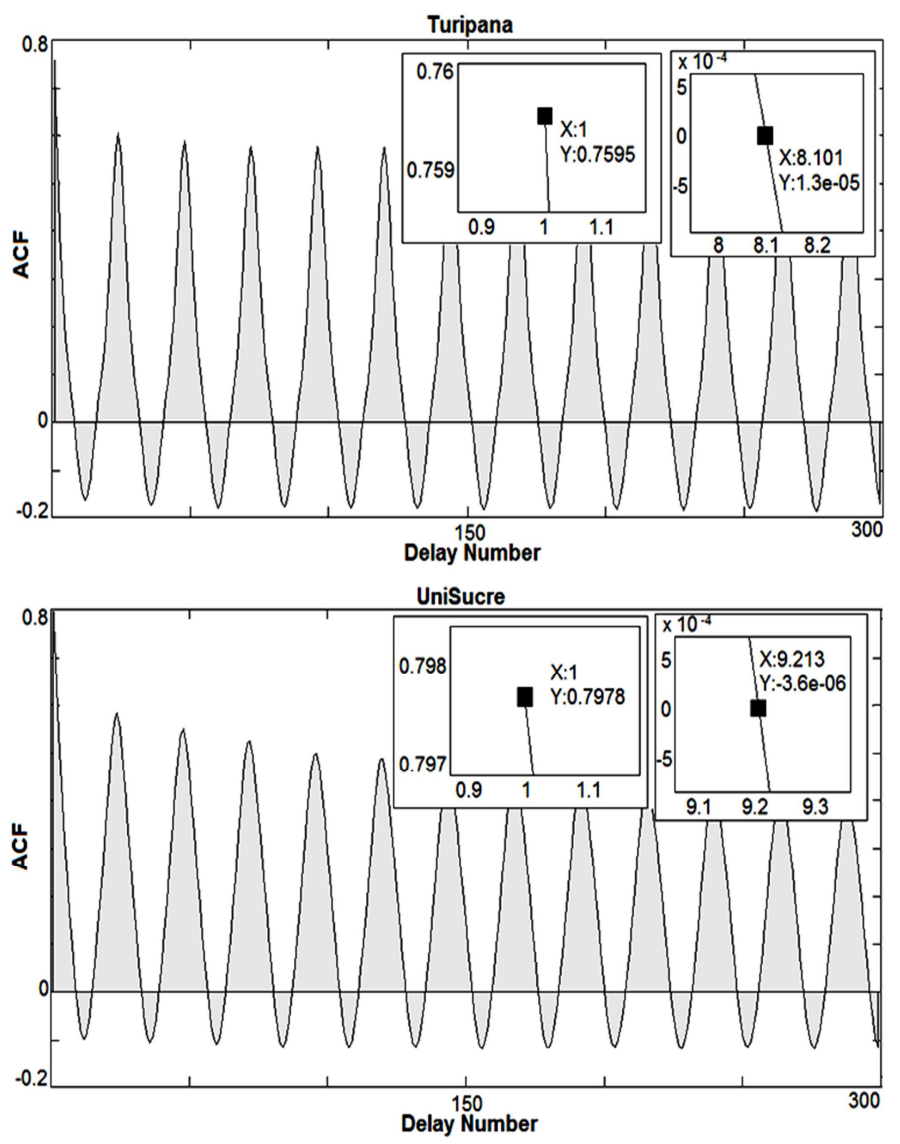

Turípana, and UniSucre, obtain their wind persistence value for the first intersection with the $\mathrm{x}$-axis. In contrast, the weather station of UniCórdoba, accepts its wind persistence value for the first minimum of the curve of the function. And using the equations indicated previously, the values shown in Table II are obtained.

TABLE II

Wind PERSistence For THe WeAther Stations

\begin{tabular}{|l|l|l|l|}
\hline Weather station & PACF & $\boldsymbol{r}_{\boldsymbol{I}}$ axis $\boldsymbol{y}$ & $\boldsymbol{K}_{\boldsymbol{0}}$ axis $\boldsymbol{x}$ \\
\hline Turipaná & 2.70 & 0.76 & 8.1 \\
\hline Los Garzones Airport & 2.10 & 0.74 & 6.68 \\
\hline UniCórdoba & 105.23 & 0.84 & 252 \\
\hline UniSucre & 3.28 & 0.80 & 9.21 \\
\hline
\end{tabular}

use of the wind direction is the UniCòrdoba weather station with a constant wind speed intensity. In contrast, the UniSucre weather station has the highest wind speed in a specific direction in the southeast.

In figure 8 the significant values for the weather stations (WS) are the following: UniSucre WS has a wind speed with more frequency between $1 \mathrm{~m} / \mathrm{s}$ and $2 \mathrm{~m} / \mathrm{s}$ in the southeast direction, UniCórdoba WS has a wind speed with more frequency Between $2 \mathrm{~m} / \mathrm{s}$ and $2.5 \mathrm{~m} / \mathrm{s}$ from southeast to west, Turipana SW has a wind speed most often between $1 \mathrm{~m} / \mathrm{s}$ and $2 \mathrm{~m} / \mathrm{s}$ from southeast to west, Apto. Los Garzones WS has a speed of wind most often between $0 \mathrm{~m} / \mathrm{s}$ and $2 \mathrm{~m} / \mathrm{s}$ from 

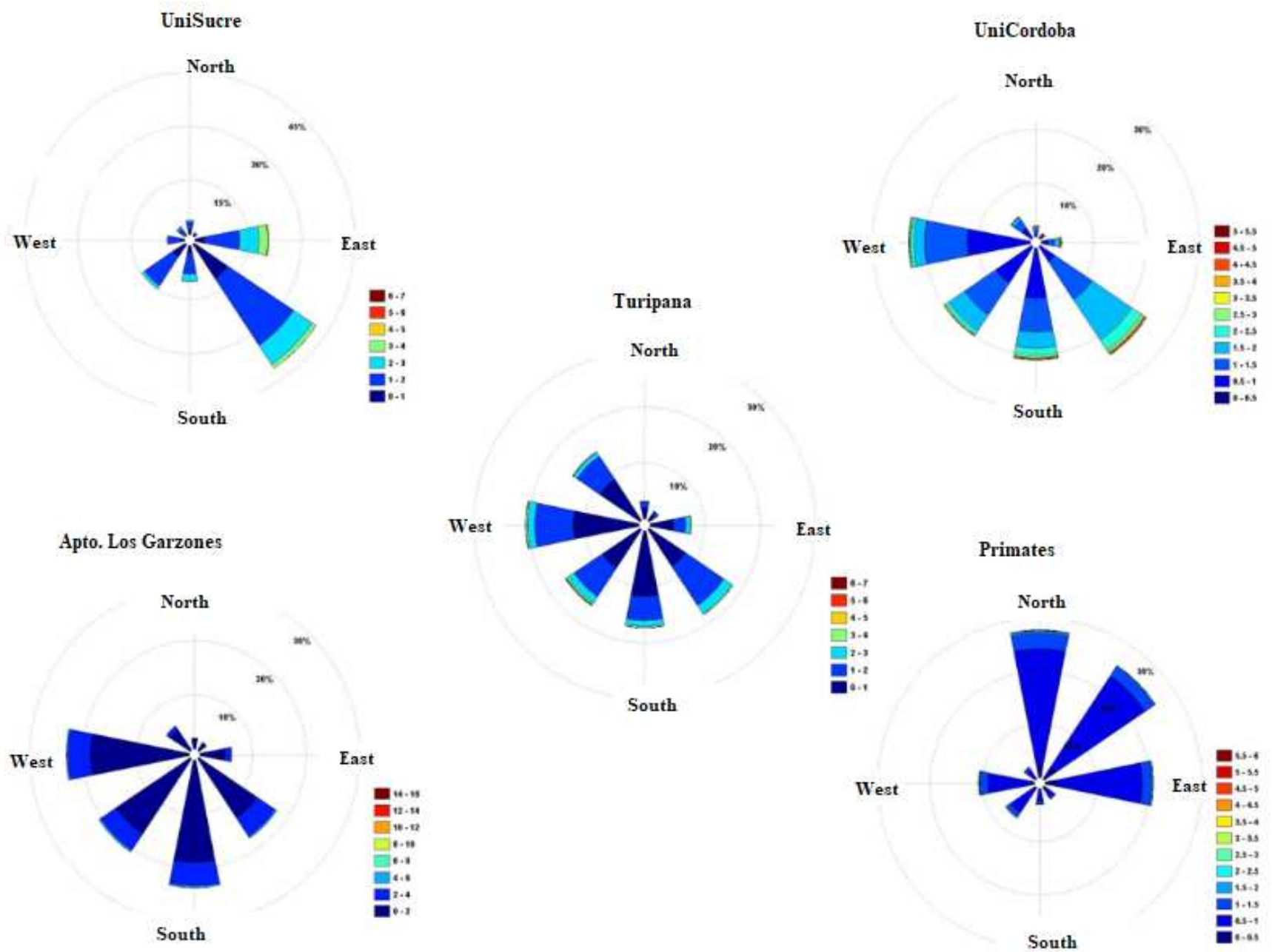

Fig. 8 Wind roses

\section{CONCLUSION}

The wind behavior was analyzed for the selected weather stations on the Departments of Cordoba and Sucre in the Colombian Caribbean Region. In terms of the results, it can be noticed that among the surveyed stations, UniCórdoba brings the highest wind persistence values among the group of stations when using the auto-correlation function. Furthermore, the Turipaná, Los Garzones Aiport, and UniSucre stations are highlighted, given that they show the higher wind persistence outcome values in the analysis. The UniCórdoba station presented the highest wind persistence value that pertains to an ACF value of 105.23 and a mean wind speed of $1.35 \mathrm{~m} / \mathrm{s}$, which shows that this station has a usable wind power potential. The mean wind speeds go from $0.85 \mathrm{~m} / \mathrm{s}$ to $1.7 \mathrm{~m} / \mathrm{s}$ among the group of surveyed stations, making this data input to analyze the usable wind potential. At last, the outcome readings of the wind roses show a constant behavior of the wind direction that allows for more meaningful use of the wind power potential at each of the stations.

\section{REFERENCES}

[1] J. Pasqualino, C. Cabrera, and M. V. Chamorro, "articulo_8 Impacto ambiental de las FNCE," pp. 68-75, 2015.

[2] N. G. Mortensen et al., "WAsP Utility Programs," vol. 2261, no September, p. 52, 2004.

[3] F. J. Ramírez, A. Honrubia-Escribano, E. Gómez-Lázaro, and D. T. Pham, "The role of wind energy production in addressing the European renewable energy targets: The case of Spain," J. Clean. Prod., vol. 196, no. 2018, pp. 1198-1212, 2018, doi: 10.1016/j.jclepro.2018.06.102.

[4] Y. Cancino-Solórzano, A. J. Gutiérrez-Trashorras, and J. XibertaBernat, "Analytical methods for wind persistence: Their application in assessing the best site for a wind farm in the State of Veracruz, Mexico," Renew. Energy, vol. 35, no. 12, pp. 2844-2852, 2010, DOI: 10.1016/j.renene.2010.05.008.

[5] Y. Cancino-Solórzano and J. Xiberta-Bernat, "Statistical analysis of wind power in the region of Veracruz (Mexico)," Renew. Energy, vol. 34, no. 6, pp. 1628-1634, 2009, doi: 10.1016/j.renene.2008.11.018.

[6] S. A. Akdat and Ö. Güler, "A novel energy pattern factor method for wind speed distribution parameter estimation," Energy Convers. Manag., vol. 106, pp. 1124-1133, 2015, DOI: 10.1016/j.enconman.2015.10.042.

[7] L. Jiang, "Mean wind speed persistence over China," Phys. A Stat. Mech. its Appl., vol. 502, pp. 211-217, 2018, DOI: 10.1016/j.physa.2018.02.058. 
[8] Z. R. Shu, Q. S. Li, Y. C. He, and P. W. Chan, "Observational study of veering wind by Doppler wind profiler and surface weather station," J. Wind Eng. Ind. Aerodyn., vol. 178, no. December 2017, pp. 18-25, 2018, DOI: 10.1016/j.jweia.2018.05.001.

[9] J. F. Villegas, G. V. Ochoa, M. V. Chamorro, I. Mecánico, G. Interdisciplinario, and D. Investigación, "Wind Speed Study and Persistence Analysis for a Set of 18 Weather Stations Located on the Colombian Caribbean Region," Int. J. ChemTech Res., vol. 10, no. 9 , pp. 1038-1045, 2017.

[10] J. F. Villegas, G. V. Ochoa, and M. V. Chamorro, "Statistical Analysis of Wind Power and Analytical Methods for Wind Persistence in Magdalena and Cesar Departments in Colombia," Indian J. Sci. Technol., vol. 10, no. 36, pp. 1-09, 2017, DOI: 10.17485/ijst/2017/v10i36/106638.

[11] J. Fabregas, G. Valencia, and M. Vanegas, "Statistical analysis and evaluation of the wind persistence for stations in Departments of $\mathrm{La}$
Guajira and San Andrés \& Providencia in Colombia," Espacios, vol. 38, no. 08, p. 14, 2017.

[12] M. Hussain, "Dependence of power law index on surface wind speed," Energy Convers. Manag., vol. 43, no. 4, pp. 467-472, 2002, DOI: 10.1016/S0196-8904(01)00032-2.

[13] K. Koçak, "Examination of persistence properties of wind speed records using detrended fluctuation analysis," Energy, vol. 34, no. 11, pp. 1980-1985, 2009, DOI: 10.1016/j.energy.2009.08.006.

[14] M. Shoaib, I. Siddiqui, S. Rehman, S. Khan, and L. M. Alhems, "Assessment of wind energy potential using wind energy conversion system," J. Clean. Prod., vol. 216, pp. 346-360, 2019, DOI: 10.1016/j.jclepro.2019.01.128.

[15] A. Bahrami, A. Teimourian, C. O. Okoye, and H. Shiri, "Technical and economic analysis of wind energy potential in Uzbekistan," $J$. Clean. Prod., vol. 223, pp. 801-814, 2019, DOI: 10.1016/j.jclepro.2019.03.140. 